\title{
Ciência política, em Goiás e na UFG
}

\author{
F. Itami Campos \\ Doutor em Ciência Política (Universidade de São Paulo) \\ Professor aposentado da Universidade Federal de Goiás \\ Goiânia, Goiás, Brasil \\ itamicampos@unievangelica.edu.br
}

\begin{abstract}
Resumo Este texto procura traçar o percurso da Ciência Política em Goiás, retomando seu início no curso de Ciências Sociais, em 1964, bem como na Universidade Federal de Goiás, recém-instalada. Para tanto, a conjuntura política e as condições sociais da universidade e do curso são analisadas. Em seguida e a partir da discussão da implantação da Ciência Política no Brasil, a trajetória da disciplina em Goiás é apresentada.

Palavras-chave: ciência política, Universidade Federal de Goiás, institucionalização
\end{abstract} das ciências sociais, história contemporânea do Brasil.

\section{Introdução}

R ecebi o convite para escrever este texto sobre a Ciência Política na R Universidade Federal de Goiás (UFG) como reconhecimento ao meu trabalho, mas também com apreensão pela dificuldade de mostrar com clareza a dimensão que esta área temática apresenta hoje na UFG e em Goiás.

Aluno da $1^{a}$ turma do curso de Ciências Sociais, com colegas dividimos as preocupações quanto à nossa formação, bem como os encargos para suprir as dificuldades e a desqualificação existente no começo do curso. Foi, sem dúvidas, uma empreitada coletiva. Desde seu início, em 1964, muitas foram as iniciativas para que as Ciências Sociais se institucionalizassem em Goiás e para que houvesse adequada profissionalização dos envolvidos.

Cabe aqui, então, resgatar a trajetória da UFG, apresentando a conjuntura do momento de sua criação e instalação, mostrando as dificuldades, e também o esforço e a dedicação que tornaram possível construir uma Universidade pública e de qualidade em Goiás.

As desigualdades regionais brasileiras ainda hoje se apresentam significativas quando se considera o número de doutores, cursos de mestrados e doutorados, revistas com Qualis, recursos para pesquisa e tantos outros indicadores de qualidade. O Centro-Oeste, o Nordeste e o Norte inscrevem-se entre as regiões mais desfavorecidas. A UFG parece destoar desse quadro, com 25 doutorados, 53 mestrados, 5 mestrados profissionalizantes, com muitas linhas de pesquisa e importantes pesquisas; está classificada em $23^{\circ}$ lugar no Brasil no ranking da Folha de S.Paulo (RUF/FSP, 2014).

Para este relato, sobre a institucionalização das Ciências Sociais, além da vivência de aluno e posteriormente de professor do curso, balizei-me em relatórios e descrições do percurso das ciências sociais no mundo e no Brasil. A Ciência Política, por sua vez, faz também parte dessas descrições, merecendo destaque novos conteúdos e avanços me- 
todológicos alcançados particularmente após o final da Segunda Guerra Mundial, em 1945.

\section{Criação da UFG, conjuntura Brasil, Goiás}

Para entendimento do processo em que a Ciência Política se implantou e se desenvolveu em Goiás, é preciso tratar da fundação da Universidade Federal de Goiás, que, criada em 14 de dezembro de 1960, de certa forma foi produto da época vivida pelo Brasil e também das condições e dificuldades de Goiás.

O período, demarcado pelo final da Segunda Guerra (1945) e o Golpe Militar no Brasil (1964), tem sido caracterizado pelo populismo (Weffort, 1978). Além disso, torna-se importante destacar também outro eixo indicador do período - o nacionalismo.

A questão nacional, marca da política Getulista e do Estado Novo, acabou por alimentar o jogo político, gerando confronto entre a esquerda e a direita, entre liberais e conservadores. Daí o confronto se estender à política externa - dada a presença e a influência dos Estados Unidos da América do Norte, em toda a América Latina e, claro, no Brasil -, gerando os desdobramentos da "guerra fria" e do pan-americanismo, além dos radicalismos ideológicos da época.

O país vivia em 1960 difíceis condições políticas, especialmente quando Juscelino Kubistchek assinou o ato de criação da UFG, em dezembro de 1960. Nas eleições nacionais, realizadas a 3 de outubro, apenas dois meses antes, a oposição a ele tinha sido vitoriosa; Jânio Quadros foi eleito presidente da República, com propostas que confrontavam as políticas e ações do Governo JK. No governo JK, o radicalismo e o golpismo estiveram presentes, muitas sendo as dificuldades enfrentadas pelo Presidente, as quais não cabe no momento discutir.

Em 1960 a população goiana era de 1.913.289 habitantes, sendo que $69,9 \%$ dela residiam no campo; Goiânia, a capital, tinha pouco mais de 300 mil habitantes, ou seja, Goiás era um estado rural tanto nas suas atividades econômicas, como na residência de sua população (Campos, 2012).

Mesmo assim Goiás vivia um momento histórico diferente - Governo de Mauro Borges Teixeira que se apresentava como moderno e planejado, trazendo a ideia de um Goiás urbano. Ao mesmo tempo, o populismo, conflitos ideológicos, o desafio de Brasília, o movimento social, reforma agrária, movimento camponês, Trombas, greves, agitação estudantil, sindicalização no campo, tudo isso se apresentava como novo, como algo desafiante (Rabelo, 1976; Campos, 2012).
A Universidade, então, torna-se produto dessa diversidade política e social. Ao mesmo tempo, houve por parte de seus dirigentes a tentativa de incorporar essa diversidade. Contraditoriamente, a Universidade Federal foi criada num momento em que predominavam as atividades rurais tradicionais em Goiás.

\section{UFG, criação, instalação}

A criação da Universidade Federal de Goiás ocorreu numa interessante conjuntura da política brasileira: Governo Juscelino Kubitschek, democracia populista, construção de Brasília, interiorização, desbravamento, Marcha para o Oeste. E também das contradições e problemas do próprio governo JK, que precisava de imunidade e de espaço político que o cargo de Senador por Goiás, posteriormente, lhe daria. [Em 1961, Juscelino foi eleito Senador por Goiás, após renúncia do senador Taciano Gomes de Melo, do PSD, a fim de abrir possibilidade para a eleição do ex-presidente.]

Vale ainda lembrar que não foi tranquilo o processo de criação da Universidade Federal de Goiás e não houve unanimidade em torno dele. Uma intensa movimentação política precedeu o ato de criação, em 14 de dezembro de 1960, pelo presidente Juscelino Kubitschek de Oliveira. Destaque-se o conflito com a Igreja em Goiás, de certa forma contrária à UFG, dada a preocupação com a consolidação da sua Universidade Católica (UCG), criada em 17 de outubro de 1959, pouco antes da UFG.

Em 1962, quando instalada, a UFG foi constituída pela incorporação das seguintes faculdades então existentes em Goiás: Direito (federalizada), Odontologia e Farmácia, Engenharia do Centro-Oeste, Medicina; incorporou também o Conservatório de Música, além da Faculdade de Filosofia, Ciências e Letras, criada na instalação da UFG. Com base nas idéias nacionalistas então hegemônicas, foi criado o Centro de Estudos Brasileiro (CEB) para ser um núcleo de ensino e pesquisa, para discutir a conjuntura brasileira e fomentar o debate sobre o Brasil.

Rapidamente, aquela conjuntura política que permitiu a implantação da UFG e a movimentação de novas forças políticas e sociais, com jornal ( $4^{\circ}$ Poder $)$ e ideias modernizantes, altera-se totalmente. O Golpe de 31 de março 1964 e a instauração do Regime Militar impuseram ao país e à Universidade uma nova ordem, autoritária, intervencionista. Com professores perseguidos, afastados e presos, também alunos afastados pelo Decreto-Lei 477 e presos, criava-se um clima de apreensão e de estímulo à delação. O Centro de Estudos Brasileiros (CEB), invadido pelas forças de segurança, com provas e trabalhos de alunos recolhidos, foi 
logo em seguida fechado, restando a alguns professores (muitos foram afastados e punidos) e aos alunos a integração à Faculdade de Filosofia e a opção por História (curso recém-criado) ou por Ciências Sociais.

$\mathrm{Na}$ época, a própria UFG sofreu intervenção, com afastamento do seu primeiro reitor, Colemar Natal e Silva, e a designação de um reitor pro-tempore pelo Ministério da Educação.

Em 1968, a Reforma Universitária, não a discutida e nem a pedida pelo movimento social, mas a gestada nos porões do MEC, tendo por base o projeto MEC/USAID, moldou a universidade brasileira. A relação da universidade com a sociedade se estabelece via Projeto Rondon, que desloca alunos e professores para lugares distantes da sede, alienando-os dos problemas políticos e sociais de sua região. Os campi foram afastados da cidade, os estudantes isolados e sua movimentação política esvaziada, além de terem seus líderes presos, coagidos e mortos. Tratava-se de um claro processo de distanciamento, de despolitização da universidade, dos seus alunos e professores.

Apesar disso, a Universidade foi espaço de muita ousadia e pioneirismo, sendo importante destacar que, ao lado da geração pioneira, de professores fundadores, em diferentes cursos e unidades da UFG, houve outro personagem também de significativa importância - o aluno - que, insatisfeito, aliou-se às forças progressistas enfrentando a tradição e o comodismo, procurando saída e alternativa para a Universidade.

\section{O curso de Ciências Sociais}

Em meio ao clima de reformismo e movimentação política, foi criado em 1963 e instalado em 1964 o curso de Ciências Sociais, integrando-se aos outros cursos da recém-criada Faculdade de Filosofia, Ciências e Letras.

Com vestibular realizado em fevereiro de 1964 , 35 alunos no ritmo político da época iniciaram o curso em $1^{\circ}$ de março. Contudo, os novos rumos da política nacional, trazidos pelo Golpe de Estado de 31 de março de 1964, fizeram com que a maioria dos alunos abandonasse o curso.

O curso não tinha uma estruturação curricular definida. A bibliografia de Ciências Sociais era inexistente. $\mathrm{O}$ quadro de professores era constituído de juristas e autodidatas (em Sociologia, Antropologia, Ciência Política e Metodologia da Pesquisa Social), o que refletia a deficiência de profissionais no Estado. Muitos professores do curso, bacharéis em Direito, pouco conheciam das ciências sociais, curso que nenhum deles havia cursado.

Em 1968, era grande a insatisfação dos alunos com os professores e com o curso, criando-se um clima de tensão e de agitação que resultou no afastamento de vários professores-juristas. Talvez devido a essa condição, os alunos da primeira turma assumiram a estruturação do curso, inclusive sugerindo ao final de cada ano a reforma da grade curricular por eles cursada. Essa movimentação foi assumida e liderada também por alunos de turmas posteriores e, em 1965, em assembleia do Curso, os alunos criam o Centro de Estudos Sociais e Políticos (CESP), órgão representativo dos alunos. O CESP promoveu muitos encontros, debates e discussões. Na sequência, sua atuação, considerada subversiva, fez com que, em 1969, sua sede que ficava nas dependências da Faculdade de Educação fosse invadida por agentes da repressão (do SNI). Na invasão do CESP, foram apreendidos documentos e livros (da iniciante biblioteca), sendo proibido o seu funcionamento a partir de então.

Para a empreitada de melhoria e estruturação do curso, os alunos buscaram apoio de professores e colegas dos Cursos de Sociologia e de Ciências Sociais da UFMG, USP e UnB. Através do CESP, foram realizadas as primeiras atividades acadêmicas do curso de Ciências Sociais: em 1965, a $1^{\text {a }}$ Semana Nacional de Sociologia, palestrante, Vilmar Evangelista Faria, sociólogo (UFMG); em 1966, 2a Semana de Sociologia, palestrante, Walber da Silva Braga, antropólogo (UFMG); em 1967, o Curso Sociologia Brasileira, por Fernando Correia Dias (UnB); e, em 1968, $3^{\text {a }}$ Semana de Sociologia, palestrante, Florestan Fernandes, sociólogo, afastado da USP pelo Regime Militar. Além disso, os alunos de Goiás integraram-se à Executiva Nacional dos Estudantes de Ciências Sociais (ENESCS), ligada à UNE, participando de Encontros Nacionais de Ciências Sociais e de tantas outras atividades nacionais, tais como as ligadas à regulamentação da profissão de sociólogo. Em 1966, foi aprovado no Congresso Nacional esse projeto de regulamentação, mas foi vetado pelo presidente Castelo Branco.

Também em 1968, os recém-formados cientistas sociais organizaram a Sociedade Goiana de Sociologia (SGS), entidade representativa dos cientistas sociais em Goiás, com estatuto registrado no Cartório Marconi de Faria Castro, sob o n. 1024/68. Contudo, o clima político repressivo, pós AI-5, impede seu funcionamento e leva à desativação da SGS. Reativada nos anos 1980, funcionou por algum tempo apenas.

Vale destacar que a Universidade, em seus primeiros anos, não dispunha de instalações para funcionamento adequado da Faculdade de Filosofia e de seus cursos, ficando muitas turmas alojadas em locais diferentes. O curso de Ciências Sociais peregrinou funcionando cada ano em um local: iniciou em 1964 em sala da Faculdade de Engenharia (Setor Universitário); no segundo ano, foi deslocado para salas do Instituto Histórico e Geográfico de Goiás (Rua 82, 
Praça Cívica); em 1966, para um prédio, alugado, na Rua 15 com a Rua 20; e, em 1967, para salas da Faculdade de Economia e Administração da UCG (Setor Universitário). Em 1968, a Faculdade foi instalada em prédio, dito próprio, no Campus da UFG, no Setor Universitário (hoje, sede da Faculdade de Educação).

A Reforma Universitária imposta pelos militares após 1968 atinge todos os cursos da Universidade. Criam-se os Institutos Básicos, também os Departamentos, organizados por área de conhecimento, e os Colegiados de Cursos, responsáveis pela organização da oferta das disciplinas e desenvolvimento do ensino, organizado pelo regime de créditos. Com a reforma, a Faculdade de Filosofia, Ciências e Letras deixa de existir, sendo dela desmembradas quatro unidades (1) Instituto de Ciências Humanas e Letras (ICHL), (2) Instituto de Matemática e Física (IMF), (3) Instituto de Química e Geociências (IQG), e (4) Faculdade de Educação.

O ICHL e a Faculdade de Educação permaneceram na Praça Universitária (no prédio hoje pertencente à Faculdade de Educação). Posteriormente, problemas estruturais do prédio fizeram com que o ICHL fosse transferido para o Seminário Santa Cruz (na Vila Pedroso, de difícil acesso, dada a precariedade da linha de ônibus na época) e, no ano seguinte, para a Faculdade de Agronomia e Veterinária (Campus II). $\mathrm{E}$, quando foram construídos os primeiros prédios do Campus II da UFG, nos anos 1970, o ICHL foi para lá deslocado. Em 1974, o ICHL e o Curso de Ciências Sociais foram instalados em seus prédios definitivos.

No início dos anos 1980, numa reação ao período pós-64 e à reforma universitária de 1968, a UFG debate e questiona o regime de créditos. Na reformulação, houve o retorno ao seriado anual, com a extinção do colegiado de cursos e com os departamentos tornando-se responsáveis pelo ensino. Novamente os cursos e currículos foram reformulados.

Acompanhando as mudanças, o curso de Ciências Sociais estruturou seu currículo tendo por base eixos temáticos, privilegiando os clássicos da Antropologia, da Ciência Política e da Sociologia.

$\mathrm{Na}$ reforma do Estatuto da UFG, em 1996, o Instituto de Ciências Humanas e Letras, na gestão do professor Itami Campos, foi desmembrado em três Unidades (1) Faculdade de Ciências Humanas e Filosofia, (2) Faculdade de Letras e (3) Faculdade de Comunicação. O curso de Ciências Sociais torna-se integrante da Faculdade de Ciências Humanas e Filosofia. Posteriormente, em nova reformulação, a Faculdade de Ciências Humanas e Filosofia deu origem a três novas unidades: Faculdade de Ciências Sociais, Faculdade de História e Faculdade de Filosofia, integradas pelos seus programas de pós-graduação (Mestrado/ Doutorado).

\section{Ciência Política no Brasil}

A constituição da Ciência Política como disciplina autônoma no Brasil é recente e, de certo modo, acompanha a trajetória da Ciência Política no mundo, conforme relatório da Comissão Gulbenkian. Vale mencionar que o cientista político norte-americano David Easton, relatando o esforço feito desde os anos 1930 para o desenvolvimento da Ciência Política nos Estados Unidos da América, apresenta o trabalho de uma comissão no início dos anos 1950, que redefine a disciplina, no que chama de revolução dual: (a) técnica, com crescente utilização de entrevistas, surveys, medidas, coleta e análise de dados; e, (b) teórica, com todo um conjunto de estudos ligados ao comportamento, em que a política é estudada numa perspectiva de análise sistêmica (Easton, 1968).

Destaque-se que no Brasil a polêmica nas Ciências Sociais não se apresenta de modo muito diferente do que o relatório da Comissão Gulbenkian relata. Inicialmente, compondo o currículo dos Cursos de Ciências Sociais, a disciplina Ciência Política se apresentava com corpo teórico definido pela Filosofia Política, Teoria do Estado e, principalmente, por uma Sociologia Política.

Nos anos 1950 e início dos 1960, os cursos de Ciências Sociais eram marcantemente orientados por teóricos franceses e alemães, adotando um enfoque teórico europeu e uma bibliografia com essa influência, o que se explica especialmente pela presença de professores europeus na USP.

Rompendo com a influência paulista - Escola de Sociologia da Maria Antônia/USP - dois núcleos de Ciência Política vão ser criados: em Belo Horizonte, na Universidade Federal de Minas Gerais (UFMG), o mestrado em Ciência Política do DCP; e no Rio de Janeiro, o mestrado em Ciência Política do IUPERJ, ambos com apoio financeiro da Fundação Ford e com professores cursando doutorado nos Estados Unidos.

A partir de então, com a Fundação Ford concedendo bolsas de estudos para estudantes brasileiros cursarem mestrado aqui (no DCP e no IUPERJ), com a vinda de pesquisadores norte-americanos e com a divulgação de autores e da bibliografia de Ciência Política norte-americana, outra orientação teórica e metodológica se difunde no Brasil.

Os mestrados criados nestes dois núcleos - os primeiros em Ciência Política no Brasil - vão se tornar importantes na formação de cientistas políticos, numa visão comportamentalista, institucional que toma como base dados empíricos. E, através de trabalhos e publicações de professores destes centros de pós-graduação, a Ciência Política passa a se afirmar numa base teórica distinta da Teoria do Estado e da Sociologia Política, funcionalista, positivista, tendo em vista, agora, o empirismo e o dado analítico, com 
orientação behaviorista, comportamental, e com ênfase na discussão de sistema político e sistema social.

\section{Ciência Política em Goiás}

Integrando o conjunto das disciplinas do curso de Ciências Sociais, a Ciência Política em Goiás era inicialmente trabalhada por advogados. A orientação, a bibliografia pouco se diferia de uma teoria do Estado, com algumas pinceladas de filosofia política. Como já foi dito as primeiras turmas do curso de Ciências Sociais da UFG tiveram como professores de sociologia, antropologia e de metodologia de pesquisa graduados em Direito, advogados e juízes, sem formação específica, nem mesmo em especializações, nas disciplinas que ministravam.

Nos anos 1970, com professores egressos do mestrado em Ciência Política do DCP-UFMG (Francisco Itami Campos, Francisco Chagas Evangelista Rabelo, Maria Alice de Lima Gomes de Menezes, Servito de Menezes Filho e Antônio Lorenzo Martinez), as ementas das disciplinas que compunham a área de Ciência Política do Curso de Ciência Sociais foram alteradas, assumindo novo enfoque e diversificação da bibliografia.

A partir do enfoque funcionalista, com base no comportamentalismo e na discussão de sistema, uma nova orientação bibliográfica começa a circular - David Aeston, Robert Dahl, Harold Lasswell, Seimour M. Lipset, Gabriel Almond, G. E. G. Catlin, Samuel Eisenstadt, Karl W. Deutsch e, principalmente, uma maior leitura de Max Weber.

\section{Especialização}

No início dos anos 1980, o departamento de Ciências Sociais era formado por muitos professores com mestrado (DCP, UnB, PUC-SP, Unicamp, História-UFG, Educação-UFG), com projetos de pesquisa em desenvolvimento e significativa participação em eventos nacionais, ANPOCS principalmente.

As condições permitiram a oferta de cursos de especialização. Coordenada pelo professor Itami Campos, foi oferecida uma especialização em "Planejamento e Políticas Sociais", com duas turmas concluindo o curso. Posteriormente, a partir de contatos com o Núcleo de Estudos de Políticas Públicas (NEPP) da Unicamp tornou-se possível a formação de uma equipe que passou a trabalhar com políticas públicas, decidindo-se oferecer especialização na área. Ainda coordenadas por Itami Campos, duas turmas de especialização em Políticas Públicas foram oferecidas, todas elas concluindo. $\mathrm{Na}$ continuidade, um convênio com a Secretaria de Planejamento do
Estado de Goiás foi realizado, com suporte da Funape, possibilitando a oferta de diversas turmas de especialização em Políticas Públicas, coordenadas, inicialmente, por Pedro Célio Alves Borges. As turmas de especialização resultaram em bons trabalhos, alguns com projetos aproveitados e com aplicação em gestão pública. Dois livros, coordenados por Francisco Rabelo e Genilda D. Bernardes, foram editados e mostram parte do que foi produzido.

\section{Mestrado}

Nos anos 1990, com o corpo docente do DCS já composto por diversos doutores teve início a articulação para a estruturação de um mestrado em Ciências Sociais. Montado o projeto, consultores da CAPES foram trazidos para avaliar e fornecer elementos para a elaboração do APCN. No início dos anos 2000, foi autorizado o funcionamento do curso de mestrado e, logo em seguida, a Ciência Política se fazia presente com seus doutores e definia linhas de pesquisa, contribuindo com estudos e pesquisas sobre Goiás e a política regional.

\section{Presença da Ciência Política na sociedade}

A questão do mercado sempre foi desafio para o concluinte das Ciências Sociais, especialmente em Goiás, com um campo de trabalho restrito e uma cultura marcantemente tradicionalista, além de certo conservadorismo que via/vê no cientista social um profissional "diferente"! Talvez por isso, a divulgação da profissão do cientista social, de sociólogo principalmente, fazia parte do trabalho de organismos estudantis e, posteriormente, da Sociedade Goiana de Sociologia.

A partir de um dado momento, com turmas concluídas, a presença de cientistas sociais no mercado, em instituições, organizações e assessorias se tornou efetiva. O magistério do ensino médio e, depois, do ensino superior tornou-se um dos principais campos de trabalho do licenciado e do bacharel em Ciências Sociais. Surge em seguida a discussão sobre a inserção de Sociologia no Ensino Médio, principalmente quando o questionamento das disciplinas Organização Social e Política Brasileira (OSPB) e Moral e Cívica intensificou-se, criticadas pelos seus conteúdos e principalmente pelos seus objetivos e imposições do Regime Militar.

Nos anos 1990, a Assembleia Legislativa do Estado de Goiás manteve durante algumas legislaturas contatos/parceria com a UFG e com o ICHL, sendo realizados cursos e atividades desenvolvidas com a 
participação de professores e profissionais de Ciências Sociais e de Comunicação. A coleção "Legislativo em Goiás", em três volumes, é resultado deste momento.

\section{Profissionalização e qualificação}

Acompanhando a qualificação das Ciências Sociais, brasileira e goiana, a área de Ciência Política do DCS diversificou-se com a presença de profissionais mestres e doutores oriundos de áreas diversas e de programas também diversos. Muitos destes, passaram a integrar o corpo docente do Mestrado em Ciências Sociais e do Doutorado em Ciências Sociais.

Como indicador da qualificação da área de Ciência Política na UFG, em 2011, foi proposto e aprovado o Programa de Pós-Graduação em Ciência Política da UFG, com Mestrado em Ciência Política, tendo como área de concentração "Estado, Comportamento Político e Instituições", programa reconhecido pela CAPES com Nota 4.

A mesma política e a diversidade de formação levaram à proposta de estruturação do curso de graduação em Relações Internacionais, aprovado pelo Conselho Universitário em 2012 e em funcionamento.

\section{A caminhada continua...}

Este texto procura mostrar o início da caminhada da Ciência Política em Goiás, tendo como elemento de discussão a história e o desenvolvimen- to desta disciplina no mundo, no Brasil. Como foi momento também de criação e instalação da Universidade Federal de Goiás, necessário se fez apresentar a conjuntura política da criação da UFG e mostrar como ela se insere no momento da política goiana e brasileira.

Embora muitas das dificuldades tenham sido superadas, os desafios continuaram a exigir empenho e dedicação. A realidade goiana tornou-se bastante diferente daquele momento de instalação do curso e da UFG. A metropolização de Goiânia, a polarização regional com Brasília, a modernização do campo com o desenvolvimento da agroindústria e a incorporação de novas tecnologias, a interiorização do ensino superior, tudo isso repercutindo na qualificação da população estadual, apresentam-se como contexto instigante ao estudo, à pesquisa e à análise política.

Ao mesmo tempo, tem-se a persistência do atraso, do tradicionalismo no Estado. Embora tenha sua economia destacada nacionalmente, Goiás mantém regiões com baixa qualificação, com índice de crescimento abaixo da média estadual, com população em decréscimo, dada a migração para outras regiões, especialmente para o Entorno de Brasília e para a periferia de Goiânia. Tudo isso, torna-se um desafio e exige do pesquisador, do estudioso um debruçar sobre esta realidade complexa.

As condições institucionais apresentam-se bem mais favoráveis pelos recursos disponíveis, pelas condições oferecidas pela UFG, e também pela qualificação do corpo docente da área de Ciência Política, expresso na consolidação das linhas de pesquisa, na sua produção qualificada, no seu trabalho acadêmico e no empenho de ir adiante.

\section{Referências}

COMISSÃO GULBENKIAN. Para abrir as Ciências Sociais. São Paulo: Cortez, 1996.

EASTON, D. Uma teoria de análise política. Tradução de Gilberto Velho. Rio de Janeiro: Jorge Zahar, 1968.

IANNI, O. Sociologia da sociologia. 3. ed. São Paulo: Ática, 1989.

HELLER, A. et al. A crise dos paradigmas em Ciências Sociais e os desafios para o século XXI. Rio de Janeiro: Contraponto, 1999.

CAMPOS F. I. Questões agrárias: bases sociais da política goiana. Goiânia: Kelps, 2012.

CAMPOS F. I.; DUARTE, A. T. O legislativo em Goiás, v. 1, 2 e 3. Goiânia: Assembleia Legislativa, 1996/1998/2002. FORJAZ, M. C. S. A emergência da Ciência Política. Revista Brasileira de Ciências Sociais, v. 12, n. 35, São Paulo, fev. 1997.
MICELI, S. História das ciências sociais no Brasil. São Paulo: Idesp/Vértice/Finep, 1990.

RABELO, F. C. E. Governo Mauro Borges: tradicionalismo, planejamento e mobilização social em Goiás, 1961-1964. Dissertação (Mestrado em Ciências Sociais) - Universidade Federal de Minas Gerais, Belo Horizonte, 1976.

RABELO, F. C. E.; BERNARDES, G. D. (Orgs.). Políticas públicas e sociedade civil. Goiânia: Cânone Editorial, 2004a.

(Orgs.). Políticas públicas e cidadania. Goiânia: Cânone Editorial, 2004b.

UFG/ICHL. Produção Acadêmica do Instituto de Ciências Humanas e Letras (ICHL). Goiânia: Ed. UFG, 1995.

WEFFORT, F. C. O populismo na política brasileira. Rio de Janeiro: Paz e Terra, 1978. 


\section{Political science in Goiás and UFG}

\section{Abstract}

The paper analyzes the path of Political Science in Goiás, Brazil. Its beginning occurred in the course of Social Sciences, in 1964, in the just founded Federal University of Goiás (UFG). In this text, the political conjuncture and the social conditions of the University are examined. Subsequently, since the discussion about Political Science in Brazil has been established, the trajectory of the subject matter is presented.

Key words: Political Science, Federal University of Goiás, institutionalization of Social Sciences, contemporary history of Brazil.

\section{Ciencias políticas, en Goiás y en la UFG}

\section{Resumen}

El artículo busca trazar la ruta de la disciplina Ciencias Políticas en Goiás, desde su inicio en la licenciatura en Ciencias Sociales en 1964, y en la Universidad Federal de Goiás, recién instalada. Para ello, se mencionan la situación política y las condiciones sociales de la universidad y de la licenciatura. A continuación, se presenta la trayectoria de la disciplina en Goiás a partir de la discusión de la implantación del campo de Ciencias Políticas en Brasil.

Palabras clave: Ciencias Políticas, Universidade Federal de Goiás, institucionalización de las Ciencias Sociales, historia del Brasil contemporáneo.

Data de recebimento do artigo: 30/10/2014

Data de aprovação do artigo: 18/12/2014 